EXTENDED REPORT

\title{
Automated superficial lamellar keratectomy augmented by excimer laser masked PTK in the management of severe superficial corneal opacities
}

\author{
J L Alio, J Javaloy, J Merayo, A Galal
}

Br J Ophthalmol 2004;88:1289-1294. doi: 10.1136/bjo.2004.045070

See end of article for authors' affiliations

......................

Correspondence to: Dr J L Alió, Instituto Oftalmológico de Alicante, C/Cabañal, 1, 03016 Alicante, Spain; jlalio@oftalio.com

Accepted 29 March 2004

\begin{abstract}
Aim: To assess superficial lamellar keratectomy augmented by excimer laser smoothening with sodium hyaluronate $0.25 \%$, for the management of superficial corneal opacities.

Methods: Consecutive procedure performed in 14 eyes ( 13 patients) with an automated microkeratome and excimer laser phototherapeutic keratectomy (PTK) smoothening using sodium hyaluronate $0.25 \%$. Main outcome measures: UCVA, BCVA, pachymetry, degree of haze, ray tracing analysis, and complications. Mean follow up was 12 (SD 1.6) months.

Results: Mean preoperative haze from previous corneal refractive surgeries was 3.5 (SD 0.5) (11/14 cases). In one case, opacity was caused by ocular trauma and in two by infectious keratitis. The mean preoperative UCVA was 0.7 logMAR (0.2 (SD 0.13) decimal value). BCVA was 0.4 logMAR (0.4 (SD 0.17 ) decimal value). Mean preoperative corneal pachymetry was 508 (SD 62.5) $\mu \mathrm{m}$ and mean opacity depth measured by corneal confocal microscopy was 115.2 (SD 49.4) $\mu \mathrm{m}$. At 6 months, $71.4 \%$ of the eyes with previous corneal refractive surgery showed grade I haze or less. Mean postoperative corneal pachymetry at 6 months was 352.36 (SD 49.05) $\mu \mathrm{m}$.

Conclusions: Automated superficial lamellar keratectomy combined with excimer laser PTK smoothening assisted by sodium hyaluronate $0.25 \%$ induces a significant improvement of corneal transparency and visual acuity in cases of corneal opacity caused by previous refractive surgery, ocular trauma, and keratitis.
\end{abstract}

$\mathrm{S}$ uperficial corneal opacities are a frequent indication for corneal grafting. The biological problems of penetrating corneal grafting, especially immunological rejection ${ }^{1-7}$ have been addressed with corneal lamellar grafting, a technique that largely prevents these problems. However, corneal lamellar grafts are often followed by a long visual recovery during the postoperative period. ${ }^{8-11}$ The recent success of laser assisted in situ keratomileusis (LASIK) has promoted the development of a new generation of instruments that can perform lamellar cuts of different depths. ${ }^{12} 13$

A new generation of corneal confocal microscopes has recently been introduced for clinical use, allowing the location of corneal opacities and other anatomical findings with very high precision inside corneal stroma. The combination of both-confocal microscopes and microkeratomesallows the use of such instruments first to determine an adequate diagnosis of the extent and depth of a corneal opacity, ${ }^{14}{ }^{15}$ and then to attempt, within certain limits, the performance of a corneal excision at a tentative precalculated level to either partially or totally remove the opacity.

However, the microkeratome cut, despite its technical improvements, is still lacking full uniformity and smoothness ${ }^{16-18}$ to result in full optical performance of the cornea. Recently it has been suggested that excimer laser surgery assisted by certain smoothening substances such as sodium hyaluronate $0.25 \%^{19}{ }^{20}$ could be eventually used to correct corneal irregularities. The use of masking substances to smooth corneas operated by excimer laser has also been the issue of previous investigations by other authors. ${ }^{21} 22$

The aim of this paper is to present the results of the combined use of automated superficial keratectomy augmented by hyaluronic acid assisted phototherapeutic keratectomy (PTK).

\section{MATERIALS AND METHODS}

Fourteen eyes (13 patients; eight males) with a mean age of 45.07 (SD 17.4) years (range 16-74 years), with different degrees of superficial corneal opacity were included. The causes of corneal opacity in the study eyes are listed in table 1.

All patients underwent ophthalmological evaluation including cycloplegic refraction, uncorrected visual acuity (UCVA), best corrected visual acuity (BCVA) converted to $\log$ MAR values for statistical analysis, slit lamp biomicroscopy examination, and corneal confocal microscopy to determine the depth of corneal opacity (Advanced Scanning Ltd, New Orleans, LA, USA), ${ }^{15} 2425$ ultrasound pachymetry (DGH-500 pachymeter, Tokyo, Japan), corneal topography (C-SCAN, colour; Ellipsoid Topometer, Technomed GmbH, Baesweiler, Germany) to determine the superficial corneal surface quality (SCSQ), and predicted corneal visual acuity.

Corneal thickness measurements were performed 48 hours preoperatively, and 1 month, 6 months, and 1 year after surgery.

\section{Corneal confocal microscopy study}

Corneal confocal microscopy was used to establish the depth at which corneal opacity was located from the corneal surface. The parameters of the confocal microscope used were X24, 0.6 NA variable working distance objective lens, a field of view of $450 \times 360 \mu \mathrm{m}$, and the $\mathrm{z}$ axis resolution of $12 \mu \mathrm{m}$. Images were captured using a video scope CCD video camera and stored on S-VHS video tape. In addition, confocal

Abbreviations: BCVA, best corrected visual acuity; CMTF, confocal microscopy through focus; ID, image distortion; LASIK, laser assisted in situ keratomileusis; PRK, photorefractive keratectomy; PTK,

phototherapeutic keratectomy; RK, radial keratotomy; SCSQ, superficial corneal surface quality; UCVA, uncorrected visual acuity. 


Table 1 Grade and maximal depth of the opacity in
each case

microscopy through focus scans (CMTF) were obtained as previously described. ${ }^{15} 2425$

Central leucoma depth was measured from epithelial surface. Using customised software, the CMTF data were digitised onto the computer, and intensity profile curves were calculated. ${ }^{25} 26$ The leucoma thickness was defined as the distance (in microns) from the beginning to the end of the bright scar tissue area in the performed $\mathrm{z}$ scan. A protocol of this study was prepared following the tenets of the Declaration of Helsinki. ${ }^{27}$ All patients included in the study had understood and signed an informed consent before the study.

\section{Surgery}

Topical oxibuprocaine $0.2 \%$ was used preoperatively. The first step of the procedure was to create a free corneal cap of

Table 2 Pachymetry measurements of each eye, depth of leucoma, free cap thickness, depth of ablation of the smooting procedure, and postoperative corneal pachymetry values $(\mu \mathrm{m})$

\begin{tabular}{|c|c|c|c|c|c|}
\hline Eye & $\begin{array}{l}\text { Pre-op } \\
\text { pachymetry }\end{array}$ & $\begin{array}{l}\text { Attempted } \\
\text { thickness of } \\
\text { the free } \\
\text { corneal cap }\end{array}$ & $\begin{array}{l}\text { Programmed } \\
\text { depth of PTK } \\
\text { treatment }\end{array}$ & $\begin{array}{l}\text { Post-op } \\
\text { pachymetry } \\
\text { at } 1 \text { month }\end{array}$ & $\begin{array}{l}\text { Post-op } \\
\text { pachymetry } \\
\text { at } 6 \text { months }\end{array}$ \\
\hline 1 & 491 & 50 & 80 & 348 & 350 \\
\hline 2 & 492 & 80 & 30 & 390 & 375 \\
\hline 3 & 476 & 100 & 30 & 332 & 360 \\
\hline 4 & 550 & 120 & 30 & 397 & 399 \\
\hline 5 & 500 & 130 & 30 & 348 & 341 \\
\hline 6 & 563 & 100 & 100 & 359 & 368 \\
\hline 7 & 610 & 260 & 75 & 281 & 281 \\
\hline 8 & 538 & 160 & 30 & 321 & 331 \\
\hline 9 & 570 & 100 & 30 & 473 & 420 \\
\hline 10 & 584 & 100 & 30 & 480 & 451 \\
\hline 11 & 408 & 90 & 30 & 360 & 281 \\
\hline 12 & 425 & 100 & 30 & 300 & 302 \\
\hline 13 & 430 & 80 & 40 & 352 & 327 \\
\hline 14 & 485 & 80 & 50 & 360 & 347 \\
\hline
\end{tabular}

Table 3 UCVA (expressed in logMAR and decimal scales) at the preoperative visit and at 1, 6, and 12 month postoperative controls

\begin{tabular}{lllll}
\hline \multirow{5}{*}{ UCVA } & logMAR & Mean & SD & Range \\
\cline { 3 - 5 } & & 0.2 & 0.13 & $0.05-0.5$ \\
Preoperative & 0.7 & 0.32 & 0.17 & $0.05-0.7$ \\
Month 1 & 0.5 & 0.32 & 0.27 & $0.05-0.9$ \\
Month 6 & 0.5 & 0.4 & 0.28 & $0.05-0.7$ \\
Month 12 & 0.4 & & \\
\hline
\end{tabular}

$8.5 \mathrm{~mm}$ diameter. Automated lamellar keratectomy was performed using automated corneal shaper (Chiron Vision, Irvine, CA, USA). Corneal cap thickness was selected according to the depth of the opacity calculated by confocal microscopy. The free corneal cap was removed carefully from the microkeratome and the eye was examined by slit lamp biomicroscopy to ensure adequate elimination of the corneal opacity. Following this, in order to improve the corneal surface irregularity, PTK mode assisted by sodium hyaluronate $0.25 \%$ was used as previously described by us in a recent study (table 2 ). ${ }^{20}$

The ablation was performed with a PlanoScan Technolas 217C excimer laser (Bausch \& Lomb, Chiron Technolas $\mathrm{GmbH}$, Dornach, Germany). After the free cap was removed, one drop of $0.25 \%$ hyaluronate (LaserVisc, TRB Chemedica International SA, Geneva, Switzerland) combined with a drop of fluorescein was instilled on the cornea. Using this combination during the ablation procedure, disappearance of the fluorescence in an area indicates complete removal of the viscoelastic masking solution. ${ }^{20}$

Following laser surgery, the stromal bed was rinsed with BSS solution and a bandage contact lens was placed. No antimitotic drugs were used. An antibiotic/steroid combination (Tobradex, AlconCusi, Barcelona, Spain) and cycloplegia (Colircusí Cicloplégico 1\%, AlconCusi, Barcelona, Spain) were prescribed every 8 hours.

The postoperative evaluation included UCVA, BCVA, refraction, pachymetry, corneal topography, image quality, and image distortion provided by the ellipsoid topometer. The visual acuity values (logMAR) were expressed in terms of mean (standard deviation).

The data obtained postoperatively were analysed using the statistical package SPSS 8.0 for Windows (SPSS Inc, Chicago, IL, USA). When the variables followed a normal distribution, the arithmetic means corresponding to each group were compared using the $t$ test or the one way ANOVA. When variables did not follow a normal distribution, a nonparametric test was used (Mann-Whitney U or ANOVA on ranks) to compare medians.

Table 4 BCVA (expressed in logMAR and decimal scales) at the preoperative visit and at 1, 6, and 12 month postoperative controls

\begin{tabular}{lllll}
\hline \multirow{2}{*}{ BCVA } & logMAR & Mecimal & \\
\cline { 3 - 5 } & & Mean & SD & Range \\
\hline Preoperative & 0.4 & 0.4 & 0.17 & $0.05-0.7$ \\
Month 1 & 0.3 & 0.5 & 0.22 & $0.1-0.9$ \\
Month 6 & 0.2 & 0.63 & 0.24 & $0.1-1.0$ \\
Month 12 & 0.2 & 0.63 & 0.35 & $0.1-0.9$ \\
\hline
\end{tabular}




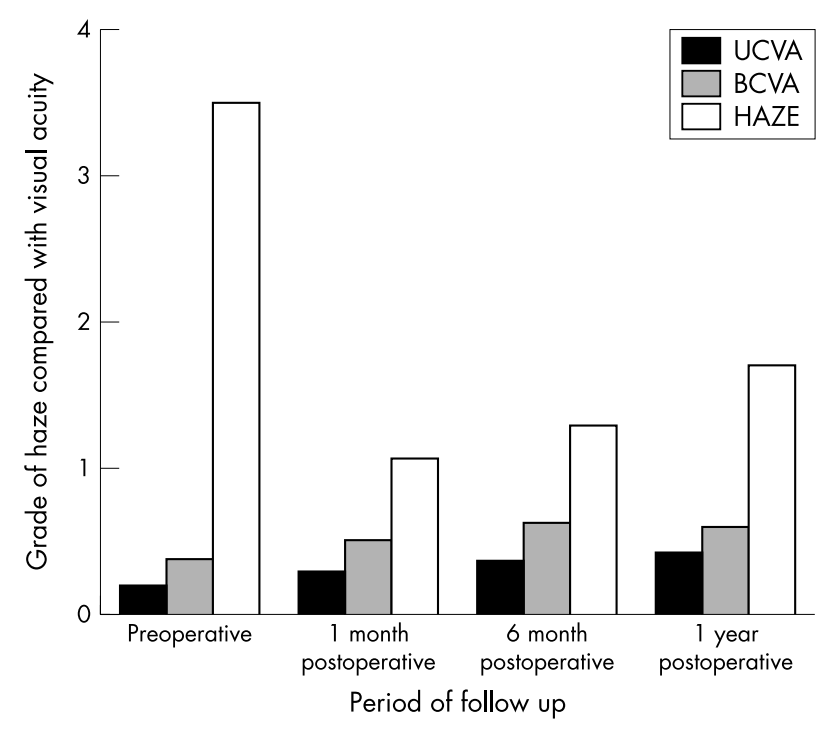

Figure 1 Bar graph showing the evolution of UCVA and BCVA with the regression of haze.

\section{RESULTS}

\section{Visual acuity}

The mean UCVA and BCVA at the preoperative visit and at 1 , 6 , and 12 months are described in tables 3 and 4 respectively.

Differences between the preoperative and postoperative UCVA were significant as calculated by $t$ test at 1,6 , and 12 months postoperatively ( $\mathrm{p}=0.01,0.03$, and 0.04 respectively).

Differences between the preoperative and postoperative BCVA were significant as calculated by $t$ test at 1,6 , and 12 months postoperatively ( $\mathrm{p}=0.05,0.001$, and 0.03 respectively). Seven eyes (50\%) gained three or more lines of BCVA, two eyes (14.3\%) gained two lines, two eyes $(14.3 \%)$ gained one line of BCVA, and three eyes $(21.4 \%)$ lost one line or more of BCVA (fig 1).

Using a decimal value (DV) of visual acuity the safety index of the procedure was 1.6 (fig 2) and the efficacy index was 0.97 (fig 3).

\section{Refraction}

The sphere and cylinder mean values and their corresponding values of standard deviation at the preoperative visit and the 1,6 , and 12 month controls are represented in table 5 .

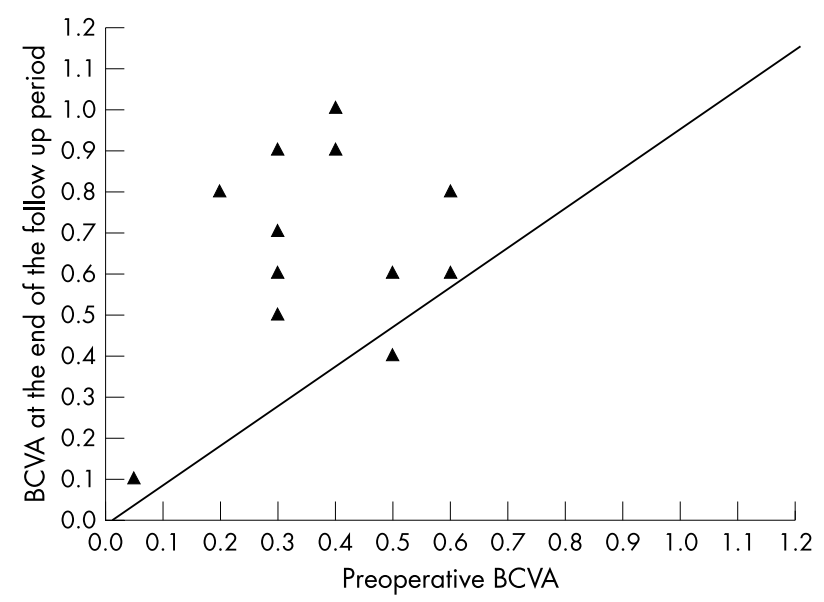

Figure 2 Scatter graph showing the safety of superficial lamellar keratectomy

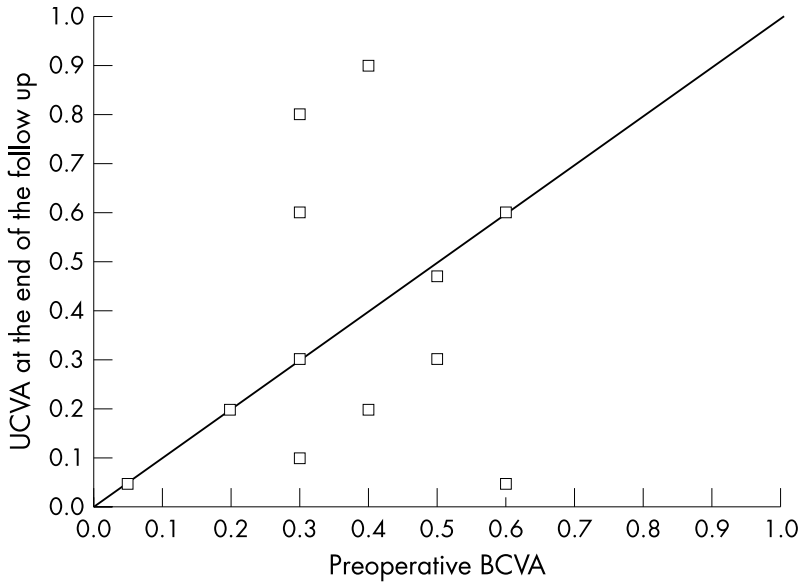

Figure 3 Scatter graph showing the efficacy of superficial lamellar keratectomy

Six months postoperatively the mean spherical equivalent was -0.56 (SD 3.9) (range -7.0 to +7.0$)$.

\section{Corneal haze and opacity}

The mean preoperative haze grade was 3.5 (SD 0.5) (range 3 to 4). A full description of evolution of haze degree through follow up period is expressed in table 6.

\section{Corneal pachymetry and treatment depth}

The preoperative and postoperative pachymetry, the attempted thickness of the free corneal cap, and the programmed depth of PTK treatments for each case are shown in table 2 .

The mean preoperative central corneal pachymetry was 508 (SD 62.5) $\mu \mathrm{m}$ (range 408-610 $\mu \mathrm{m}$ ). The mean preoperative leucoma depth obtained by confocal microscopy was 115.2 (SD 49.4) $\mu \mathrm{m}$ (range 75-260 $\mu \mathrm{m}$ ). The mean intraoperative flap thickness was 110.7 (SD 50.1) $\mu \mathrm{m}$ (range 50-260 $\mu \mathrm{m}$ ). The depth of the corneal opacity determined the ablation depth performed by using PTK. In 10 eyes an ablation depth

Table 5 Sphere and cylinder (mean, standard deviation, range) at the preoperative visit and at 1, 6, and 12 month postoperative controls (considering last surgery)

\begin{tabular}{|c|c|c|c|c|c|c|}
\hline & \multicolumn{3}{|l|}{ Sphere } & \multicolumn{3}{|c|}{ Cylinder } \\
\hline & Mean & SD & Range & Mean & SD & Range \\
\hline $\begin{array}{l}\text { Pre- } \\
\text { operative }\end{array}$ & -0.8 & 3.1 & -6 to +6.5 & -2.28 & 2.0 & -7 to +0.5 \\
\hline $\begin{array}{l}\text { Month } 1 \\
\text { Month } 6 \\
\text { Month } 12\end{array}$ & $\begin{array}{l}-0.46 \\
+0.19 \\
-0.07\end{array}$ & $\begin{array}{l}3.09 \\
3.5 \\
1.23\end{array}$ & $\begin{array}{l}-6 \text { to }+5 \\
-6.75 \text { to }+6 \\
-1.75 \text { to }+1.5\end{array}$ & $\begin{array}{l}-1.78 \\
-1.4 \\
-1.8\end{array}$ & $\begin{array}{l}1.41 \\
1.95 \\
1.9\end{array}$ & $\begin{array}{l}-6.75 \text { to } 0.0 \\
-1.75 \text { to }-1.5 \\
-6 \text { to } 0.0\end{array}$ \\
\hline
\end{tabular}

Table 6 Degree of haze at the preoperative visit and at 1,6 , and 12 month postoperative controls

\begin{tabular}{llllll}
\hline \multicolumn{5}{c}{ Degree of haze, number (\%) } \\
\cline { 2 - 6 } & $\mathbf{0}$ & I & II & III & IV \\
\hline Preoperative & $3(21.4 \%)$ & $8(57.1 \%)$ & $2(14.3 \%)$ & $1(7.1 \%)$ & $7(50 \%)$ \\
Month 1 & $3(1.1 \%)$ & $9(64.3 \%)$ & $4(28.6 \%)$ & & $1(7.1 \%)$ \\
Month 6 & $1(7.1 \%)$ & $4(28.6 \%)$ & $2(14.3 \%)$ & & $1(70 \%)$ \\
Month 12 & $7(50 \%)$ & 4 &
\end{tabular}


Table 7 Technomed C scan topometer values of superficial corneal surface quality (SCSQ) preoperatively and at 12 month controls

\begin{tabular}{lllll}
\hline & SCSQ & Image distortion (ID) & Change of SCSQ & Change of ID \\
\hline Preoperative & $68.18 \%$ (SD 13.9) & 13.86 (SD 6.32) & & \\
& $(53.13$ to 87.38) & $(6.4$ to 25.6) & & \\
12 months & $88.56 \%(S D ~ 5.84)$ & $10.08(S D 2.68)$ & $+18.5 \%$ (SD 13.15) & -3.77 (SD 6.06) \\
& $(81.25$ to 96.88$)$ & $(6.4$ to 15.2) $p=0.09$ & (improvement) & (reduction of ID) \\
& $p=0.005$ & & & \\
\hline
\end{tabular}

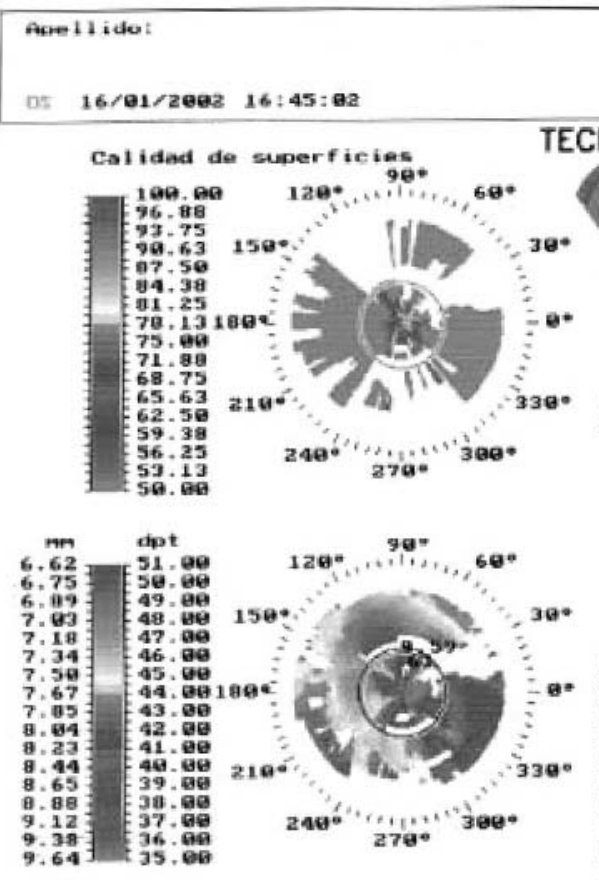

Figure 4 Topography (Technomed) of the left eye showing the degree of image distortion following a complicated LASIK procedure. (A) Preoperative. (B) Following superficial lamellar keratectomy, the image shows a reduction of image distortion.

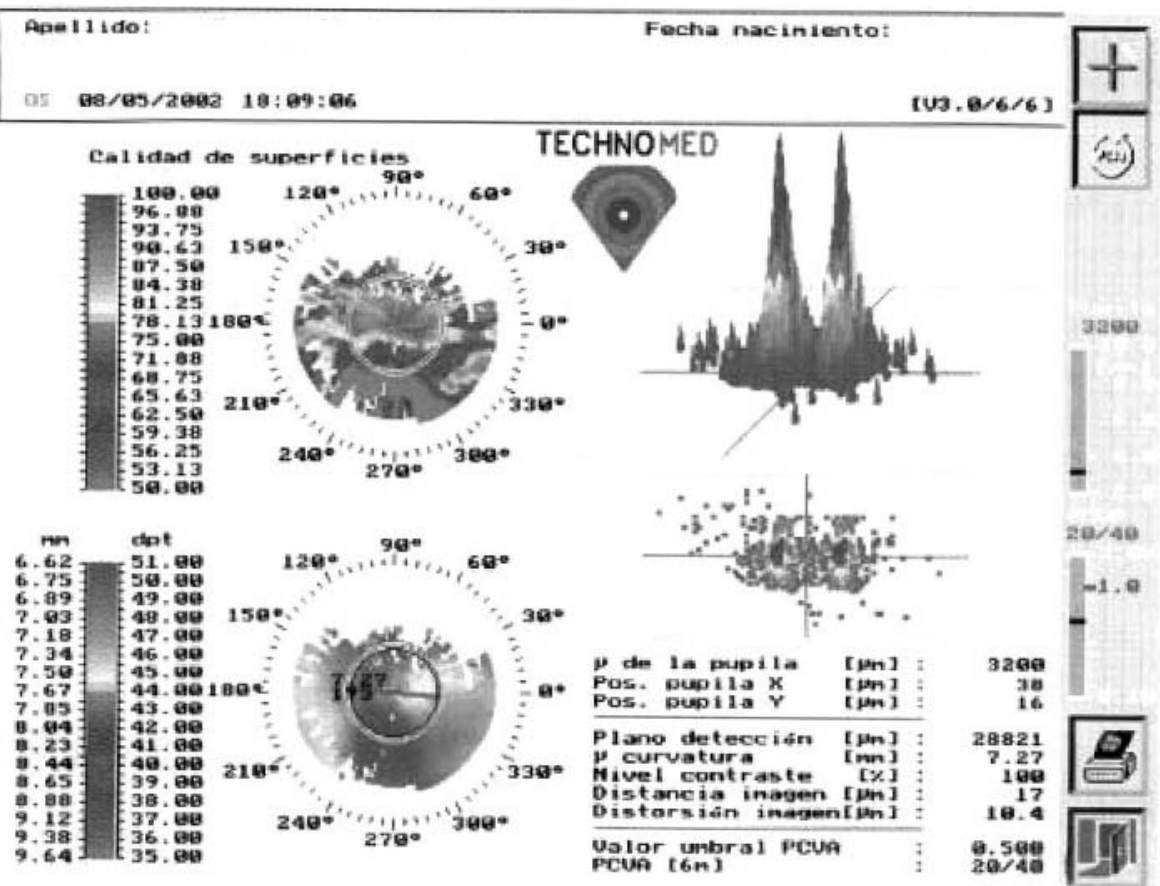


of $30 \mu \mathrm{m}$ was used and an ablation depth of 50, 75, 80, and $100 \mu \mathrm{m}$ were used respectively. The mean postoperative central corneal pachymetry at 1 month was 364.3 (SD 56.6) $\mu \mathrm{m}$ (range $281-480 \mu \mathrm{m}$ ). The mean postoperative central corneal pachymetry at 6 months was 352.36 (SD 49.05) $\mu \mathrm{m}$.

\section{Image distortion}

Mean (SD) values and ranges of superficial corneal surface quality (SCQS), image distortion (ID), change of superficial corneal surface quality ( $\delta$ SCSQ), and the change of image distortion ( $\delta$ ID) preoperatively and at the end of the follow up are shown in table 7. Both SCQS and ID dramatically improved after surgery $(p=0.005$ and $p=0.09$, respectively).

An example of the improvement of the Tecnomed parameters is shown in figure 4 .

\section{Complications}

Only one eye $(1 / 14,7.14 \%)$ showed poor results during the follow up period. This case had a history of multiple previous excimer laser procedures. The preoperative UCVA was 0.7 $\log$ MAR (0.2 DV) and could not be improved because of a corneal haze grade IV. The corneal pachymetry measured $430 \mu \mathrm{m}$ in corneal thickness. Six months after the procedure the patient's UCVA remained unchanged but his BCVA improved by using SoftPerm (Cibavision, GA, USA) contact lens +4.5 diopters (gas permeable contact lens) to 0.1 $\log$ MAR (0.8 DV). The pachymetry measured $360 \mu \mathrm{m}$ corneal thickness and the haze decreased to grade II. After one year, the UCVA declined to $1.00 \log$ MAR $(0.1 \mathrm{DV})$ and the BCVA was $0.8 \log$ MAR $(0.16 \mathrm{DV})$ due to relapse with depth of haze extending up to $100 \mu \mathrm{m}$ (confocal microscope) and clinically the cornea showed haze grade IV. This patient had a pachymetry around $350 \mu \mathrm{m}$ and the decision was taken to perform PKP as a final solution to the haze problem and to restore the visual acuity.

\section{DISCUSSION}

Corneal opacity haze is one of the serious consequences of corneal refractive surgery and frequently causes low BCVA. Faint anterior stromal opacifications are a common finding after photorefractive keratectomy (PRK) procedures. $^{28-30}$ Various treatment strategies have been proposed including topical steroids, mechanical debridement, and retreatment with excimer laser. ${ }^{32-34}$ Years ago, PK was considered to be the procedure of choice for treatment of this complication. Unfortunately, PK is associated with a prolonged recovery period for visual rehabilitation, and the risk of transplant rejection or high astigmatism, especially irregular type, is a concern. $^{35}$ The persistent need to develop a method for managing the problem of haze and opacity has given rise to continuous investigation in the field.

Automated lamellar keratoplasty has historically been used as a refractive procedure for treatment of myopia but with low predictability. ${ }^{37}{ }^{38}$ Because of the irregular success rate of alloplastic transplantation of the corneal cap, ${ }^{39}$ excision of the complete disc that includes the corneal tissue might be an alternative in certain cases and, if the procedure fails, it is still possible to perform PKP. Such an alternative has been previously reported as successful but in a very limited report. ${ }^{35}$

Smoothness of the lamellar keratectomy is one of the most important factors in avoiding irregular astigmatism after any lamellar refractive surgery. This smooth surface is always suboptimal when compared with an excimer laser ablated surface. For this purpose a smoother technique using excimer laser was combined with the procedure. ${ }^{20}$ Excimer laser application in the PTK mode has been used successfully to treat superficial corneal opacities. ${ }^{40}$
The goal of the hyaluronic acid assisted PTK procedure was to improve the corneal stromal smoothening and to decrease the probability of haze regression. Slit lamp examination revealed significant decrease of haze in all cases with improvement of the UCVA and the BCVA.

With regards to the improvement of vision after 6 months, more than $60 \%$ of the patients had UCVA of $0.5 \log$ MAR (0.32 DV) or more and 30\% had UCVA of 0.2 logMAR $(0.63$ DV) or more. Nearly $80 \%$ of the patients had BCVA of 0.3 logMAR (0.5 DV) or more and 50\% had BCVA of 0.2 logMAR $(0.63 \mathrm{DV})$ and more. Corneas showed a decrease in corneal haze after 6 months to grade I or less in almost $70 \%$ of eyes, and grade II in almost $30 \%$ of eyes. Although regression of some degree of haze occurred at the end of the first year, over $90 \%$ of the eyes still had haze grade II or less. Only one eye (7.1\%) had haze grade IV and this patient was scheduled for PKP procedure. The patients were subjectively improved in all cases. The improvement in the clinical situation of the patients parallelled the improvement shown in the parameters of image distortion of the Technomed topography images. In all cases, SLK avoided either lamellar or penetrating corneal graft for the correction of the severe corneal irregular astigmatism suffered by the patients.

One obvious consequence of this procedure is the induction of corneal thinning (table 2), which requires prolonged follow up to study its biomechanical effects and stability. It should be remembered that in all of our cases this procedure was used as an alternative to avoid corneal grafting procedures and the uncertainties associated with that. This surgery does not prevent corneal grafting should it be required in future.

No vision threatening complications were observed during the follow up of this study. Apart from haze regression in a few cases that required no further treatment and did not clinically affect the visual function of the patients, one eye required PKP one year after the SLK. In spite of the secondary procedure performed in three of 14 eyes $(21.4 \%)$, none lost any lines of BCVA and no case developed further corneal complications following the procedures.

\section{CONCLUSION}

Automated superficial lamellar keratectomy augmented with hyaluronic assisted PTK has proved to be an alternative to corneal grafting for management of severe superficial corneal opacities. Further studies are required to assess the minimal corneal thickness acceptable for a normal biomechanical and functional stability of the cornea.

\section{Authors' affiliations}

J L Alio, J Javaloy, Instituto Oftalmológico de Alicante (Department of Cornea and Refractive Surgery) and Department of Ophthalmology, Miguel Hernández University, Medical School, Alicante, Spain A Galal, Clinical fellow at the Instituto Oftalmológico de Alicante (Department of Cornea and Refractive Surgery), Miguel Hernández University, School of Medicine, Alicante, Spain

J Merayo, Insituto de Oftalmobiología Aplicada. Universidad de Valladolid. Spain

This study has been supported in part by a grant of the Spanish Ministry of Health, Instituto Carlos III, Red Temática de Investigación en Oftalmologia, Subproyecto de Cirugia Refractiva y Calidad Visual (C03/13).

\section{REFERENCES}

1 Biswas S, Suresh P, Bonshek RE, et al. Graft failure in human donor corneas due to transmission of herpes simplex virus. Br J Ophthalmol 2000;84:701-5. 2 Naacke HG, Borderie VM, Bourcier T, et al. Outcome of corneal transplantation rejection. Cornea $2001 ; 20: 350-3$.

3 Lee HM, Naor J, Alhindi R, et al. Detection of hepatitis C virus in the corneas of seropositive donors. Cornea $2001 ; 20: 37-40$.

4 Jonas JB, Rank RM, Budde WM. Immunologic graft reactions after allogenic penetrating keratoplasty. Am J Ophthalmol 2002;133:437-43. 
5 Reinhard T, Bohringer D, Huschen D, et al. Chronic endothelial cell loss of the graft after penetrating keratoplasty: influence of endothelial cell migration from graft to host. Klin Monatsbl Augenheilkd 2002;219:410-16.

6 Reinhard T, Bocking A, Sundmacher R. Chronic endophthalmitis mimicking an endothelial immune reaction after penetrating keratoplasty. J Cataract Refract Surg 2002;28:1475-7

7 Rumelt S, Bersudsky V, Blum-Hareuveni T, et al. Preexisting and postoperative glaucoma in repeated corneal transplantation. Cornea 2002;21:759-65.

8 McDonnell PJ, Falcon MG. The lamellar corneal graft for optical indications. Eye 1988;2:390-4.

9 Shimazaki J. The evolution of lamellar keratoplasty. Curr Opin Ophthalmol 2000;11:217-23.

10 Xie L, Shi W, Liu Z, et al. Lamellar keratoplasty for the treatment of fungal keratitis. Cornea 2002;21:33-7.

11 Melles GR, Remeijer L, Geerards AJ, et al. A quick surgical technique for deep, anterior lamellar keratoplasty using visco-dissection. Cornea 2000; 19:427-32.

12 Ludwig K, Bechmann M, Welge-Lussen U, et al. New automated microkeratome for trepanation of lamellar keratoplasty. Ophthalmologe 2002:99:384-9.

13 Hafezi F, Mrochen M, Fankhauser F 2nd, et al. Anterior lamellar keratoplasty with a microkeratome: a method for managing complications after refractive surgery. J Refract Surg 2003;19:52-7.

14 Ivarsen A, Bertho AT, Stultiens BS, et al. Validation of confocal microscopy through focusing for corneal sublayer pachymetry. Cornea 2002:21:700-4.

15 Moller-Pedersen T, Vogel M, Li HF. Quantification of stromal thinning, epithelial thickness and corneal haze after photorrefractive keratectomy using in vivo confocal microscopy. Ophthalmology 1997;104:360-8.

16 Wilhelm F, Giessmann T, Hanschke R, et al. Cutting edges after automatic lamellar keratotomy. Klin Monatsbl Augenheilkd 1998;213:293-300.

17 Keuch RJ, Bleckmann H. Comparison of 3 microkeratomes used for keratomileusis in situ in a swine model. $J$ Cataract Refract Surg 1999;25:24-31.

18 Wilhelm FW, Giessmann T, Hanschke R, et al. Cut edges and surface characteristics produced by different microkeratomes. J Refract Surg 2000:690-700.

19 Artola A, Alió JL, Bellot JL, et al. Protective properties of viscoelastic substances (sodium hyaluronate and $2 \%$ hydroxymethyl cellulose) against experimental free radical damage to the corneal endothelium. Cornea 1993; 12:109-14.

20 Alio JL, Belda Jl, Shalaby AM. Correction of irregular astigmatism with excimer laser assisted by sodium hyaluronate. Ophthalmology 2001;108:1246-60

21 Corbett MC, Pyrdal Jl, Verma S, et al. An in vivo investigation of the structures responsible for corneal haze after photorefractive keratectomy and their effects on visual function. Ophthalmology 1996;103:1366-80.

22 Kornmehl EW, Steinert RF, Puliafito CA. A comparative study of masking fluids for excimer laser phototherapeutic keratectomy. Arch Ophthalmol $1991 ; 69: 641-6$.
23 Alio JL, Artola A, Claramonte PJ, et al. Complications of photorefractive keratectomy for myopia: Two years follow up. J Cataract Refract Surg 1998;24:1-7

24 Linna T, Tervo T. Real-time confocal observations on human corneal nerves and wound healing after excimer laser photorefractive keratectomy. Curr Eye Res 1997; 16:640-9.

25 Li HF, Petroll WM, Møller-Pedersen T, et al. Epithelial and corneal thickness measurements by in vivo confocal microscopy through focusing (CMTF). Curr Eye Res 1997:16:214-21.

26 Petroll WM, Jester JV, Cavanagh HD. Quantitative 3-dimensional confocal imaging of the cornea in situ and in vivo: system design and calibration. Scanning 1996;18:45-9.

27 Hutchinson D. Declaration of Helsinki. In: The trial investigator's GCP handbook: a practical guide to ICH requirements. Richmond, UK: Brookwood Medical Publication Ltd, 1997:44-7.

28 Allemann N, Charmon W, Silverman RH, et al. High frequency ultrasound quantitative analyses of corneal scarring following excimer laser keratectomy Arch Ophthalmol 1993;111:968-73.

29 Andrade HA, McDonald MB, Liu JC, et al. Evaluation of opacity lensometer for determining corneal clarity following excimer laser photoablation. Refract Corneal Surg 1990;6:346-51.

30 Caubet E. Causes of subepithelial corneal haze over 18 months after photorefractive keratectomy for myopia. Refract Corneal Surg 1993:9:65-70.

31 Dastgheib KA Clinch TE, Manche EE, et al Sloughing of corneal epithelium and wound healing complications associated with laser in situ keratomileusis in patients with epithelial basement membrane dystrophy. Am J Ophthalmol 2000; 130:297-303

32 Carr JD Patel R, Hersh PS. Management of late corneal haze following photorefractive keratectomy. Refract Corneal Surg 1995;11(suppl):309-13.

33 Fitzsimmons TD, Fagerholm P, Tengroth B. Steroid treatment of myopic regression: Acute refractive and topographic changes in excimer photorefractive kertaectomy patients. Cornea 1993;12:358-61.

34 Gartry DS, Kerr Muir M, Lohmann CP, et al. The effect of topica corticosteriods on refractive outcome and corneal haze after photorefractive kertaectomy: A prospective randomized, double-blind trail. Arch Ophthalmol 1992; 110:1209-19.

35 Rasheed K, Rabinowitz YS. Superficial lamellar keratectomy using an automated microkeratome to excise corneal scarring caused by photorefractive keratectomy. J Cataract Refract Surg 1999;25:1184-7.

36 Koay PYP, McGhee CNJ, Weed KH, et al. Laser in situ keratomileusis for ametropia after penetrating keratoplasty. J Cataract Refract Surg 2000;16:140-7.

37 Bas AM, Nano HD JR. In situ myopic keratomiluesis. Results in 30 eyes at 15 months. J Refract Corneal Surg 1991;7:223-31

38 Arenas-Archila E, Sánchez-Thorin JC, et al. Myopic keratomiluesis in situ. Preliminary report. J Cataract Refract Surg 1991;17:424-35.

39 Elkins BS, Casebeer JC, Kezirian GM. Sutureless homoplastic lamellar keratoplasty. J Refract Surg 1997;13:185-7.

40 Fagerholm P, Fitzsimmons TD, Orndahl $M$, et al. Phototherapeutic kertaectomy: long-term results in 166 eyes. J Refract Corneal Surg 1993:9:76-81. 